\title{
A productive NHS
}

\section{Gareth lacobucci senior reporter}

The BMJ

As the NHS in England grapples with the longest funding squeeze in its history, the quest for greater productivity becomes ever more pressing.

Two new analyses published this week show that the productivity of consultants in NHS hospitals has fallen over the past six years. The authors reject any notion that this means doctors need to work harder but argue that we need to rethink how we seek and measure productivity in the NHS.

In his latest data briefing John Appleby crunches productivity numbers and finds that the average productivity per consultant in NHS hospitals in England fell by 3\% between 2009 and 2016 (doi:10.1136/bmj.j1520).

But Appleby highlights a problem. In his view, comparing elective activity with numbers of consultants-the typical method for assessing consultant productivity in NHS hospitals-fails to adjust for what he calls "the quality of the product." He acknowledges that adjusting for quality is not easy but says that failing to do so means that consultant productivity can be "seriously underestimated over time."

In a separate analysis researchers from the Health Foundation pinpoint poor workforce planning as the chief cause of falling consultant productivity (doi:10.1136/bmj.j1552). To illustrate, they highlight that the number of NHS consultants has risen by $22 \%$ over the past six years, whereas the number of nurses rose by just $1 \%$. As this report's coauthor Anita Charlesworth points out on BMJ Opinion (http://blogs.bmj.com/bmj), the NHS must improve its workforce planning if it wants to get the most out of its consultant workforce and to avoid further cuts to staff nurse training numbers, a damaging short term measure that has harmed productivity.

The Health Foundation also notes the wide variation among hospitals in productivity of consultants, echoing Patrick Carter's 2015 review of productivity in NHS hospitals (doi:10.1136/bmj. h3228). Will Stahl-Timmins's infographic highlights the characteristics associated with higher consultant productivity, including more nurses and support staff working with consultants, fewer delays in transfers of care, and competitive pay rates (http://bit.ly/2nwS7VJ).

None of this is rocket science, but all of it needs to be factored in.

Of course, many elements of healthcare are difficult to quantify. As the UK comes to terms with last week's horrific attack on civilians in Westminster, Anne Gulland reports on the swift and courageous response of medical staff and emergency services (doi:10.1136/bmj.j1515). The vivid firsthand account by an anaesthetist at one of the trauma centres that treated casualties reminds us of the immeasurable resilience and professionalism shown by doctors every day. 